\title{
ANÍSIO TEIXEIRA: DILEMAS EDUCACIONAIS E POLÍTICOS DO SEU E DO NOSSO TEMPO
}

\author{
Ana Waleska Mendonça (in memoriam) ${ }^{1}$ \\ Jaqueline Moll \\ Libânia Xavier ${ }^{3}$
}

\begin{abstract}
RESUMO: Nesta entrevista, do final de 2016, na Pontifícia Universidade Católica do Rio de Janeiro (PUC-Rio), as Profas. Ana Waleska Mendonça (falecida em 2017) e Libânia Xavier, falam das ideias e da obra de Anísio Teixeira. Inscrevem-no em seu tempo, refletindo a luz dos desafios atuais. Entre os temas abordados: Plano Nacional de Educação (PNE) de 1962, formação de professores, prolongamento do tempo escolar, educação integral, experiências pedagógicas, diálogo com $\mathrm{D}$. Ribeiro e outros. O diálogo abriu pontes com a atualidade, na perspectiva anisiana de que os intervalos democráticos vividos pelo Brasil não permitiram a consolidação de um sistema educacional universal e de qualidade.
\end{abstract}

Palavras-chave: Anísio Teixeira. Políticas educacionais. Educação integral.

\footnotetext{
${ }^{1}$ Pontifícia Universidade Católica do Rio de Janeiro - Rio de Janeiro (RJ), Brasil. ${ }^{2}$ Universidade Federal do Rio Grande do Sul - Porto Alegre (RS), Brasil.

E-mail: jaquelinemoll@gmail.com

${ }^{3}$ Universidade Federal do Rio de Janeiro - Rio de Janeiro (RJ), Brasil.

E-mail: libanianacif@gmail.com
}

DOI: $10.1590 / C C 0101-32622019219122$ 


\section{Anisio Teixeira: educational and political dilemmas of his and our times}

ABSTRACT: In this interview, from the end of 2016, at Pontifícia Universidade Católica do Rio de Janeiro (PUCRio), Professors Ana Waleska Mendonça (deceased in 2017) and Libânia Xavier talk about the ideas and work of Anísio Teixeira. They inscribe it in their time, reflecting the light of present challenges. The topics covered include: PNE of 1962, teacher training, lengthening of school time, full-time education, pedagogical experiences, dialogue with D. Ribeiro and others. The dialogue has now opened bridges, from the Anisian perspective that the democratic intervals experienced by Brazil did not allow the consolidation of a universal and quality educational system.

Keywords: Anísio Teixeira. Educational policies. Full-time education.

Em dezembro de 2016, no contexto das atividades de pós-doutoramento da entrevistadora, nas dependências da Pontifícia Universidade Católica do Rio de Janeiro (PUC-Rio), a Profa. Ana W. Mendonça (PUC-Rio), precocemente falecida no ano 2017, e sua companheira de trabalho Profa. Libânia Xavier (Universidade Federal do Rio de Janeiro - UFRJ), discorrem sobre as ideias e a obra de Anísio Teixeira, apontando suas potências, suas contradiçóes, seus desafios e suas possibilidades. Inscrevem-no em seu tempo e são provocadas a pensá-lo à luz das perplexidades do contexto contemporâneo brasileiro, com os recuos que começavam a ganhar espaço.

Jaqueline Moll (JM): Gostaria que traçassem um paralelo, comparando o tempo histórico que precedeu a saída de Anísio Teixeira da vida pública e o atual. $\mathrm{O}$ contexto de construçáo do primeiro Plano Nacional de Educação (PNE) bem como suas consequências para a educação brasileira...

Ana Waleska Mendonça (AWM): Quando a gente pensa naquele primeiro PNE que foi elaborado no âmbito do Conselho 
Federal da Educação e se você se pergunta... Qual era a composição do Conselho naquele contexto? Era Anísio, acho que era Abgar Renault... Era gente ligada à educação, então tem essa marca... Ele chega a ser aprovado no Congresso. Mas logo depois o Jango cai. O Plano na verdade não chegou a ser implementado. Uma das coisas que eu acho interessante é como Anísio incorporou o plano... No livro $E d u$ cação não é privilégio (TEIXEIRA, 1957), ele incorporou quase na íntegra o contexto, aquilo foi uma estratégia para dizer: "Olha, pelo menos essa memória fica registrada”. Se você lê o plano de 1963, as bases e a lógica do Fundo de Manutenção e Desenvolvimento do Ensino Fundamental e de Valorização do Magistério (FUNDEF), os percentuais são mais ou menos os mesmos, está posta lá. É uma coisa que sempre chama muito a atenção.

JM: E o atual PNE? Estamos diante de uma Proposta de Emenda à Constituição (PEC) que talvez congele por 20 anos os investimentos em educação. Será que estamos vivendo um momento muito parecido historicamente?

AWM: Eu acho que a gente está vivendo um momento muito mais complexo. Não sei se é mais complexo, mas é diferente. Ninguém sabe muito bem o que vai acontecer. Acho que tem esse conservadorismo dando muita força, no campo da educação, esse projeto escola sem partido é uma coisa assustadora. E está começando a ter um impacto em alguns Estados.

Libânia Xavier (LX): Eu acho que nós estamos vivendo um momento também de retrocesso, em todos esses avanços que tivemos nos últimos 20 anos em termos de inclusão racial, de gênero, social. Com relação à formação de professores e à qualificaçáo, que chamam de formação continuada, eu vejo também um retrocesso, com todos esses cortes. A gente está num momento em que se avançou muito em relação ao período dos anos 1950 e 1960, e eu acho incrível que o Anísio previa em tudo o que ele escrevia e nos projetos que ele implementou. Ele estava o tempo todo preocupado com a universalização do ensino, democratização. Mas ele era muito parcimonioso também, tinha uma rede menor e a educação era uma bandeira a se considerar. Acho que hoje ela está muito desgastada como bandeira política. 
A meu ver, Leonel Brizola foi o último homem público que levantou com firmeza essa bandeira.

$J M$ : Ele tinha o desafio de dar escala, pensar como gestor, ponto de vista de quem tem a responsabilidade pública. Como é o ponto de vista de quem tem de dar escala para as coisas? Há aqui uma tensão.

AWM: Se você comparar a situação atual p'ra de 1950, 1960, mudou... É verdade. Outra coisa que eu estava me lembrando. A mãe da Tânia Dauster (Prof. PUC-Rio), professora do Instituto (de Educação), tinha uma visão muito crítica das propostas do Anísio. Pena que eu não cheguei a conhecê-la. Uma das coisas do início, nas escolas experimentais, ainda na década de 1930, os professores que estavam atuando nas escolas foram muito resistentes à proposta do Anísio. Ele acabou optando por priorizar os professores recém-formados, que estavam saindo do Instituto. É outra questão interessante.

$L X$ : É outra questão interessante. Outra coisa que, posteriormente, o Darcy Ribeiro também fez, contratando professores em formação para atuarem nos Centros Integrados de Educação Pública (CIEPs).

AWM: O Darcy resolveu criar um corpo paralelo (Secretaria Extraordinária/Programa Especial de Educação). Eu lembro que na época foi uma das questóes mais problemáticas.

JM: Anísio Teixeira entendia como um impasse: como construir um sistema escolar para uma nação, cuja aspiração de progresso o requer, mas cuja situação real não o determina? Em que medida avançamos desse impasse considerando o acesso à educação básica, o financiamento, a relação entre os entes da União?

$L X$ : Parece que a gente não consegue avançar do clientelismo, do uso político-partidário da escola, da indicação da direção e até de professores públicos. Acho que isso é um obstáculo importante. Parece que é quase atávico na educação, mas eu não quero com isso dizer que o professor é imerso nesse clientelismo e não pode sair... Em sua tese de doutorado, Fábio Garcez de Carvalho estudou o processo de emancipação do município de Icapuí, Ceará, após o qual se seguiram 20 anos de administração do Partido dos Trabalhadores (PT) (CARVALHO, 2013). Ele estudou a passagem do professor leigo para 
o professor funcionário público. Como o leigo virava professor? Sendo alfabetizado, ele era indicado por uma liderança comunitária e essa liderança conseguia que um político da região pagasse o salário dele e, assim, ele vai constituindo-se professor. Depois de muito trabalhar em condições precárias, após a organização da região em município autônomo, ele se torna funcionário púbico. Eu tenho ido a muitas bancas também da Baixada Fluminense e tenho observado que em muitos municípios dessa regiáo a indicação política ainda é muito praticada, mesmo nos lugares que têm concurso. Da emancipação até o município se firmar politicamente, o clientelismo torna-se moeda de troca de favores e de reconhecimento. Como lidar com isso, como contornar esse problema... esse é um aspecto importante. Anísio Teixeira e Fernando Azevedo batiam muito nisso.

AWM: Eu penso mais na profissionalização. O Fernando Azevedo, nos anos 1930, quando era diretor da gestão pública, ele fala em continuidade. Tentou fazer concurso público. Os vereadores tinham todas as listas de indicação e se revoltaram, quase que o prefeito não consegue colocar em prática (aprovar) o orçamento, porque houve uma quebra de braço danada. Essa é uma questão da qual não sabe muito bem como sair.

$J M:$ Tem a ver com a construção do Estado.

AWM: Com base no critério universal, no conhecimento do professor, que valide a certificação.

$L X$ : Algumas vezes, foca-se demais na questão da formação inicial e me parece que essa não é uma questão central, hoje em dia.

AWM: Mas Anísio tinha uma visão também nas duas, entende? Se você pensar em termos da profissão, da carreira. Como é que se dá a incorporação desse professor no sistema, da inserção dele. A gente chamaria a qualidade do trabalho do professor.

$J M$ : Os processos formativos, visão de universidade, essa incorporação que o então Ministro Capanema faz da Universidade do Distrito Federal (UDF). Isso vai acabar determinando no Brasil um certo modelo de formação de professores que é o que a gente tem ainda.

$L X:$ Sobretudo, tem de destacar essa separação entre teoria e prática. 
AWM: Os alunos aqui da pedagogia por meio do Programa Institucional de Bolsas de Iniciação à Docência (PIBID)... fazem a formação prática em um centro de educação infantil, uma escola bem montada ali no Leblon. Por exemplo, tinha uma professora excelente que estava trabalhando com os meninos. O que está fazendo o município agora? Ele está realocando os professores e deixando como educação infantil os professores que têm só curso normal. Essa professora era uma professora que trabalhava há muito tempo na educação infantil, era o que ela gostava, era dela. A professora fazia um trabalho fantástico e aí ela estava sendo forçada a ir para as séries iniciais no ensino fundamental, sair da educação infantil, contra a sua vontade e sem que se considerasse a qualidade do seu trabalho nesse nível de ensino. Isso é muito complicado.

JM: Outra referência importante na obra de Anísio Teixeira é a explicitação de uma visão crítica sobre nossos moldes mal copiados de educação acadêmica e intelectualista. Podemos dizer que nos últimos 50 anos demos passos na direção de construir um modelo nacional, próprio, que responda as nossas necessidades como país? Que rompa com o caráter propedêutico e livresco? Em que medida os exames nacionais, copiados do Programme for International Student Assessment (PISA), não reiteram o "caráter colonial", ênfase das políticas atuais?

$L X$ : Esse caráter livresco, que você está falando, se reproduz mesmo com os índices do PISA. O que o PISA analisa em termos de habilidade cognitiva, tem todo um linguajar que segue um padrão e é complicado. Eu acho que não tem reflexão dos limites e dos potenciais dessas avaliaçóes. A gente avançou muito pouco, então acaba reproduzindo inadvertidamente essa cultura livresca.

AWM: Acho que tem quase um sistema mundial instalado, algo instalado com muita força e é difícil romper com isso. Acho que desse ponto de vista se está muito mais assediado de fora, os padróes estão propostos de fora, isso realmente amordaça.

$J M:$ Tem a ver com grandes interesses econômicos...

AWM: Aí é o grande problema, tem a ver com grandes interesses econômicos. 
JM: Anísio Teixeira insistia em processos de emancipação educativa: não me parece que estamos aqui para disciplinar a educação brasileira, mas para promovê-la e questionar o caráter oficial sempre dissociado da realidade brasileira. Sua ênfase era no movimento, não na disciplina. Não aprendemos nada em mais de 50 anos?

$L X$ : Não sou tão pessimista. Tenho entrevistado professoras. Um grupo que entrevistei do CIEP Gustavo Capanema na Maré (que hoje não funciona mais em horário integral). O grupo participou do Programa Especial de Educação (PEE). E eu entrevistei três diretoras, elas são absolutamente apaixonadas pela escola e não abrem mão de discutir o próprio trabalho e de ter educação de jovens e adultos (EJA) na escola. A secretaria já falou: "Fecha a EJA porque tem tiroteio, já morreu um aluno lá dentro, vítima de bala perdida, mas elas insistem, porque têm um compromisso, um engajamento com os alunos que te deixa empolgada, acreditando na possibilidade de melhoria da educação".

$J M$ : Vai muito para além das determinaçóes do Estado.

$L X$ : É a partir destes problemas que a gente vê que em algumas escolas existe luz...

AWM: Eu vejo na PUC também, as experiências, a mobilização em torno do PIBID que está aí... agonizante. E como você conecta? Existem experiências muito interessantes no âmbito do sistema público, e professores extremamente compromissados. Eu me lembro das experiências que eram relatadas nas escolas. Para mim, o grande problema é como se consegue de alguma forma socializar essas experiências que acabam ficando muito episódicas e pulverizadas. Como é que se consegue de certa maneira aproveitar, explorar o potencial que essas experiências trazem e fazer com que isso tenha, em alguma medida, impacto nas políticas, porque a sensaçáo é que tem as políticas por um lado e a escola pelo outro. A sensação é de uma absoluta dissociação.

$L X$ : Tem uma medida do Anísio, de quando ele estava na direção do Instituto Nacional de Estudos e Pesquisas Educacionais Anísio Teixeira (Inep), que previa bolsa de estudos para os professores se formarem em viagens de intercâmbio. Vinha gente da Bahia para cá, como a 
gente faz na universidade, o que enriquece a bagagem cultural desses professores e os torna mais seguros de suas opçóes pedagógicas.

AWM: Ele era muito isso. Ele previa centro de formação de professores. O pessoal vinha do Nordeste para cá. Ele tinha essa ideia de que os professores formados nas instituiçóes locais deveriam circular e conhecer outras instituições e centros de formação (MENDONÇA; XAVIER, 2008).

$J M$ : Um tema recorrente nos escritos (e na prática) de Anísio Teixeira é o prolongamento do período escolar. Passados mais de 60 anos, não conseguimos avançar nesse tema como seria necessário, de forma sistemática, sustentável e universal. Como leem essa dificuldade? Como Anísio compreendia a organização curricular para esse tempo prolongado e como esse debate dialoga com a profusáo de experiências atuais de ampliação de jornada?

$L X$ : Nas escolas experimentais do Rio de Janeiro, além da Escola Parque, Anísio previa várias possibilidades de organização do horário integral ou de horário ampliado, alargado. É isso que eu acho interessante também, uma escola que era também uma escola experimental secundária, que vai ser de acordo com o que a escola propóe, um reconhecimento da autonomia de cada escola em escolher o projeto que considera (ou considere) mais adequado [...]. Cada escola experimental aqui do RJ tem um projeto pedagógico, isso é bacana. A Escola Parque é como se fosse um modelo, o que, mais tarde, veio a se tornar um modelo também para os CIEPs. O que acho interessante é isso; e pela experiência que eu adquiri trabalhando lá na implantação dos CIEPs no PEE, não dá para trabalhar com padrão, isso causa desperdício, sobreposiçóes. A meu ver, o ideal seria prever várias modalidades de horário escolar e deixar que as pessoas tenham possibilidade de escolher, tanto o aluno quanto os gestores das escolas. Isso pode ser mais complicado em termos de gestão. Mas ter isso em mente ajuda a organizar as demandas e as ofertas escolares com mais eficácia.

AWM: É interessante a preocupação do Anísio. Ele aliava essa preocupação com a ampliação do tempo de permanência da criança na escola, com o projeto de educação integrada. Essa expressão contraturno chega a ser irritante, acho isso um horror, com toda 
sinceridade. $\mathrm{O}$ que estou vendo, muitas vezes, na escola é que se amplia o tempo de permanência, mas não se oferece uma educação de qualidade... acaba reproduzindo, duplica aquilo que já está se fazendo e que não está dando certo ou fazendo acréscimos sem articulação. Você não pensa de fato a qualidade do ensino que está oferecendo, mantém, reproduz, duplica aquele currículo mais do que tradicional. Isso não resolve o problema [...]. Meu primeiro trabalho foi numa escolinha particular, fui trabalhar na escola que minha tia era vicediretora, funcionava ali na Rua São Salvador, chamava Colégio São Marcos [...] era primário e ginásio. Tinha um grupo de crianças que permanecia o dia inteiro na escola, então à tarde se desenvolvia uma coisa que eles chamavam de estudo dirigido e era interessante porque tinham monitores, eu comecei como monitora, por grupos de disciplinas, ajudando as crianças a estudar, algumas vezes você dava uma orientação geral. Óbvio que ainda era uma coisa muito tradicional. Quando a gente pensa, por exemplo, nas propostas, na experiência da Escola Parque, tinha muito de iniciação ao trabalho, das atividades manuais, a questáo da arte, que também vai estar no projeto do Darcy. No projeto original dos CIEPs, a arte tem uma enorme centralidade, então acho que não é só ampliação do tempo de permanência dentro da escola, mas é uma escola diferenciada. E eu não vejo muito isso acontecer; para dizer a verdade, eu não estou vendo nada... Essas avaliaçóes externas, gente... Uma das coisas mais interessantes a que assisti aqui na PUC foi o seminário do PIBID, vem os professores das escolas parceiras. Lembro de um professor de filosofia que diz: "Olha, a gente tem um tempo de aula por semana no ensino médio, voltou a filosofia, a gente tem uma avaliação bimestral, como é que eu vou fazer uma avaliaçáo?”. Isso é uma coisa absolutamente contraditória. "O que que eu vou avaliar?". O impacto desse sistema de avaliação está sendo muito negativo. A escola perde inteiramente a autonomia que ela tem sobre um componente que é fundamental, que é a avaliação do ensino. E a escola não tem como interferir, está tão cerceada.

$L X$ : Tendo como referência a tese do Gledson Pinheiro (2015) contextualizada na escola experimental Manuel Bomfim, durante a gestão de Anísio, dá para gente perceber que existia um controle exacerbado das atividades da escola. O controle se dava 
mais ou menos assim: a aluna escrevia a redação e, dependendo do que ela falasse, a redação ia para prof. da disciplina para uma coordenadora da psicologia e depois, se fosse o caso, poderia bater no gabinete do chefe de setor Ortofrenia e Higiene Mental, que, no caso, era Artur Ramos. Foi no arquivo dele que Gledson achou o diário de uma aluna chamada Dalila, que se enquadrava nos casos de "crianças-problema" que constituíam objeto de estudo de Ramos. Aí você percebe essa mentalidade, de uma geração anterior, conservadora, mas que está com Anísio nesse projeto de levar a criança a elaborar uma racionalidade considerada superior. Tem de ver esse aspecto do controle. Por outro lado, havia projetos extremamente envolventes, como o que é descrito no livro da professora baiana Teresinha Eboli (1969), intitulado "Uma escola diferente". Sobre esse experimento pedagógico, a avaliação da professora é a seguinte: "olha, não mudou a vida de ninguém, mas eles tiveram uma infância legal, foi uma experiência marcante e boa”.

JM: Mas aí me ocorre uma outra coisa: eu coordenei o Mais Educação e ele sempre foi pensado como uma ação indutora, não como uma política. Será que é possível mais do que induzir os municípios a fazerem outras coisas? Claro que aqui tem o aspecto de não ter chegado, mas em muitos lugares chegou. Será que é possível mais do que o governo federal induzir políticas? O risco da Base Nacional Comum Curricular (BNCC) é querer desenhar a rotina da escola e os conteúdos do dia a dia. E sobre a escola do diário de Dalila. Será que dá para generalizar isso como a ênfase das escolas experimentais de Anísio Teixeira?

$L X$ : Você falou uma coisa importante. Que tipo de investimento os gestores podem fazer para que as escolas criem uma cultura de criatividade, para que os professores saibam criar, usar o recurso que têm e não ficar esperando essa dádiva? Não sei como é que faz isso, acho que essa é a coisa mais difícil. Dá para considerar que é um jogo de tensões, mas é necessário fazer esse contraponto também.

JM: Como construir um sistema escolar para uma nação cuja aspiração nunca foi fazer-se para todos? Em que medida avançamos nesse impasse?

$L X$ : Acho que sim, e a pátria educadora ainda está servindo de slogan. E toda essa política do PT [...] mostra um projeto de nação 
com certeza, [...] a gente já tem quase $50 \%$ de alunos negros e pardos nas universidades, a política de cotas já está fazendo um equilíbrio na universidade pública. E não é à toa que a universidade pública será a mais castigada, a universidade pública vai sofrer muito mais. [...] $\mathrm{Na}$ medida em que a gente avança, os opositores a esse avanço se colocam.

AWM: A gente está vivendo um processo extremamente complicado que se remete à privatização da educação pública por dentro. Eu acho que é muito mais [...]. Aqui no Rio de Janeiro, a interferência dessas fundaçôes nas políticas públicas... a Fundação Ayrton Senna, Roberto Marinho etc. Essas empresas que estão se especializando em vender material. Fundação Lemann! Acho que é uma das coisas muito complicadas, o que está no momento atual, de fato, definindo as políticas.

JM: Tem uma frase do Darcy Ribeiro, muito dita por aí: "A crise da educação brasileira não é uma crise, ela é um projeto".

LX: Por exemplo, os Institutos Federais de Educação (IFETs) compóem uma política importante que faz a diferença para o desenvolvimento econômico.

$J M$ : Qual o projeto do país em termos da sua inserção econômica no mundo? O Mangabeira Unger diz que o Brasil é um protetorado dos EUA e que nenhuma política nossa muda isso.

$A W M$ : Desse ponto de vista, eu veria uma certa semelhança com o contexto daquela época. Quando a gente pensa em 64, o projeto que venceu foi um projeto de desenvolvimento via internacionalização da economia brasileira, internacionalização como submissão, e eu acho que o risco que a gente está correndo de novo agora é esse.

$L X$ : Se é para comparar, a gente olhou muito para formação de professores e para carreira docente. Havia um investimento. O Anísio tinha o desejo de promover uma reforma mais profunda, mais ampla na educação, como formação, qualificação, intercâmbio, e eu acho que isso se perdeu. Darcy tenta com a formação em serviço e a formação inicial em nível superior.

$A W M$ : Eu acho que nunca se voltou. Quer dizer, se você pensar naquele projeto de formação de professores. Nunca mais... tivemos um projeto nacional de formação de professores, integrado com diversidade. 
JM: A democracia não trouxe de volta!

JM: As escolas como protagonistas, não só como objeto de formação das universidades. Mas isso não volta com a democracia, por ignorância ou por intencionalidade. Não volta, Anísio...

$L X$ : De certo modo, alguns princípios com os quais Anísio operou em sua trajetória na educação foram retomados, guardadas as particularidades de cada contexto histórico. Todo esse movimento que nos anos 1980 a gente tem de reformulação curricular no Rio Grande do Sul, em Minas Gerais, no Rio de Janeiro. [...] Houve uma profusão de projetos de democratização da escola, da sua integração com a sociedade - que é riquíssima; Luís Antônio (Cunha) registra a experiência não só municipal, mas também estadual, depois em âmbito nacional a gente tem vários projetos (CUNHA, 1999).

$A W M$ : Não se conseguiu muito configurar um projeto nacional, acho que esse é o problema, o grande problema. De fato, um projeto nacional a gente não conseguiu articular. E aí você tem iniciativas que são pontuais, desarticuladas.

$J M$ : E a troca do grupo político no poder leva embora tudo isso porque não tem investimento de maioridade institucional. Eu acho que tem uma visão de tutela do Estado sobre as escolas e as configuraçóes partidárias são determinantes.

$L X$ : Em alguns casos, há uma expectativa das escolas, dos gestores das escolas, de serem tutelados. Por vezes, algumas escolas não formam uma cultura de autonomia profissional, parece. Mas, mesmo com isso, eu náo acho que a ideia de um projeto nacional se perdeu. Eu acho que nos governos do PT existiu um projeto de nação, no qual a educação comparece. Acho que o (programa) Bolsa Família ${ }^{1}$ é um exemplo, não de centralidade da educação, mas de sua articulação a outros setores no projeto nacional defendido, que articula segurança alimentar, saúde e educação... Isso é inédito na nossa experiência e acho muito importante.

JM: A figura de Anísio Teixeira atravessa a vida de muitos pensadores brasileiros. Paulo Freire menciona-o na sua tese, em 1959, apesar de não falar dele na volta do exílio. Darcy Ribeiro refere-se a ele como a 
inteligência mais brilhante que conheceu e é explicitamente seu discípulo. Como foi o diálogo entre Anísio e esses pensadores?

$A W M$ : Isso ainda existe, mas, em geral, quando você fala do Anísio eu vejo que tem uma certa resistência ao Anísio Teixeira, é muito engraçado, isso ainda existe de certa maneira.

$L X$ : Com o Paulo Freire, acho que o diálogo é pequeno porque estão em frentes totalmente diferentes.

JM: Paulo Freire vai para o Ministério da Educação (MEC) numa época que o Anísio tinha presença muito forte.

$L X$ : Eu considero que não há uma oposição entre eles, ambos queriam um ensino mais democrático, uma escola democrática, que a educação servisse de instrumento para a democratização. Paulo Freire vai trabalhar com adultos, analfabetos, em um sistema informal. E Anísio é o oposto, trabalhando com crianças e no sistema formal. É de se esperar que não tenha um diálogo muito intenso, mas com certeza um respeitava o outro, são referências diferentes. Acho que o Paulo Freire é o outro lado, tem a ver com o catolicismo. Agora com o Darcy, eu li o Confissóes (RIBEIRO, 1996). É mais o Darcy falando do Anísio, minha interpretação é que ele viu no Darcy alguém que poderia prosseguir, materializar o seu projeto de educação democrática...

AWM: De certa maneira, tentou formar o Darcy. Alguém que desse continuidade.

$L X$ :E fez sucesso. Tanto ele quanto Fernando (Azevedo) com Florestan Fernandes partilhavam uma concepção humanista e democrática com diferentes matizes. Havia alianças ente eles, ainda que suas posiçóes políticas não fossem idênticas.

$J M$ : Essa visão de antagonismos nos atrapalha muito em termos de desenvolvimento do país. Há entre nós esse grande campo humanista, que tem várias cores. É como se a gente não pudesse conversar.

$L X$ : Você falou a palavra-chave humanismo, pensar em educação nessa chave. 
$J M$ : É uma palavra proscrita, porque as palavras são muito proscritas... A gente fica muito sem chão, é um silêncio, porque tudo tem história.

$J M:$ E a relação dele com o John Dewey? Porque o Dewey é outro proscrito... Tem uma visão interessante de democracia, muito mais como vivências democráticas.

$A W M:$ Tem um texto dele sobre democracia como ideia moral, é muito interessante porque era muito a perspectiva dele da democracia.

$L X$ : É não só da democracia, mas da profissionalização do campo. E articulando teoria e prática que Anísio vai tentar trazer quando fala de formação de professores - é não só o trabalho de formação inicial, mas é o trabalho em serviço. É aquele tempo que o professor vai ter para refletir sobre a sua prática, para refazer sua prática, que é a proposta da escola laboratório trazida para cá.

AWM: Para registrar a sua prática.

$L X$ : Tudo que a gente não tem nas escolas públicas é um tempo para o professor refletir sobre o seu próprio trabalho. Entáo é preciso criar, na organizaçáo do trabalho docente, um tempo para reflexáo e para o estudo.

$J M:$ No PNE tem a proposição do tempo de formação com o piso salarial, um terço do tempo de formação.

$A W M$ : Se você pensar, de alguma maneira, a própria escola como um espaço de formação.

$J M$ : Sim, a escola como espaço de formaçáo incide sobre a vida dos professores mais, muitas vezes, que a formação inicial. Anísio pensava nesta relação: formação na Universidade-formação na Escola. Como estudiosas de Anísio Teixeira, acham que começamos a pensar nele, de novo, depois de tantos anos?

$L X$ : Ótima pergunta, porque eu acho que passou, quando a gente defendeu as nossas teses...

$A W M$ : Foi um impacto na época.

$L X$ : Penso que a disputa interna no campo da pesquisa, na universidade também, impede que você eleja alguns clássicos, os nossos 
fundadores, como qualquer área tem e cultua, e a gente não consegue isso porque é uma área muito diversa e a disputa é muito acirrada. Por outro lado, a nossa área cresceu muito em termos de pesquisa, de construção de um conhecimento propriamente pedagógico/educacional.

AWM: Estou pensando assim: até de repente se lê Anísio, mas não se pensa no que essa leitura do Anísio poderia trazer, digo, para o que estamos fazendo, agora. Se instaurou um procedimento no campo da educação meio imediatista, em que você não avança... Tem aquele texto do Peter Burke (2007), que na verdade foi uma palestra. É um texto que de vez em quando eu volto a ele e que apresenta as seguintes questóes: Quando é que termina a tradição e começa a inovação? O que é tradição e o que é inovação? Ele fala inclusive da possibilidade de haver uma tradição de inovação. Eu não uso esse termo. Mas é uma noção que nos falta.

$L X$ : Até que ponto também a gente, da história da educação, tem muito prurido em fazer uma ponte com o agora e acaba que as pessoas não percebem a atualidade e a relevância de refletirmos sobre as questóes do nosso passado.

JM: O pensamento de Anísio é contemporâneo em muitos aspectos e tem algo de atemporal. Tenho trabalhado com essa ideia de maioridade institucional. A partir da visão de emancipação educativa. Não acredito em nenhuma mudança que seja de novo vertical. Penso que essa base (BNCC) é um engodo, porque será uma peça para afinar mais os grandes interesses que vão produzir livros, as editoras, a avaliação e outras coisas que drenam os recursos da educação. São milhôes gastos nisso. Ficando para trás as questóes de carreira, salário, estrutura de escola.

AWM: Quando a gente pensa nos investimentos, na coisa que o Governo, por meio do Ministério da Educação, fez em torno dos Parâmetros Curriculares Nacionais (PCNs), publicados em 1997... Gente! Foi um enorme investimento, se trouxe até o pesquisador espanhol César Coll para assessorar o processo de elaboração dos PCNs... ${ }^{2}$.

$J M$ : Isso não entrou na escola. $\mathrm{O}$ Rei está nu... porque tu não consegues trazer a escola junto. 
AWM: Essa é uma estratégia que não se mostrou adequada. Não leva a muita coisa.

JM: Se o Anísio vivesse hoje, quais seriam suas perplexidades com o Brasil e a educação brasileira?

AWM: O Anísio tem uns últimos textos bem amargos. Para ele, a Segunda Guerra e a bomba atômica tiveram um forte impacto...

$L X$ : Ele continuaria batalhando na educação, e acho que isso a gente incorporou de alguma maneira. Para não ficar tão pessimista, acho que ele fez parte de um movimento que nos sensibiliza ainda hoje. A experiência dele serve para nos dizer que a educação pública é uma causa nobre para as nossas vidas e para a vida de todos. É uma bandeira para gente abraçar. Ele nos dá essa lição de humanidade.

$A W M:$ Dá, é verdade.

$L X:$ Eu acho que ele estaria fazendo isso e eu vejo esse compromisso em muitos profissionais de hoje. O pessoal que participou de gestão sabe, a cada fim de projeto e de governo, é deprimente você ver as pessoas perdendo os seus cargos e vendo o seu trabalho ser desmontado, uma humilhação, é uma destruição de tudo... As pessoas ficam doentes, mas não se rendem, elas voltam e elas vão recriando aquilo em que acreditam. Acho que é uma coisa legal de estudar, a gente está entrevistando os gestores [...] você circula de município para município ou de momento político para momento político. As pessoas voltam! O grupo de professores que participou do PEE compóe uma elite que foi para a universidade manter, de alguma maneira, essa ideia viva. Essas diretoras do CIEP da Maré seguiram mantendo uma prática de continuidade, mesmo com o projeto extinto. E é bom a gente tentar tornar isso objeto de estudo para ver que nem tudo resulta em uma política de terra arrasada.

JM: Mas sobre o Anísio hoje...

AWM: Quando você olha para ele, foi uma pessoa profundamente coerente. Ele brigou até o final. Pena essa coisa da desistência da defesa daquilo que ele considerava essencial. 
LX: Lembra de uma fala da Clarice Nunes, em 2001, fortíssima, uma conferência de abertura da Associação Nacional de Pós-Graduação e Pesquisa em Educação (ANPED) [...]. Ela falava dos desertos que o Anísio atravessou e dizia: "volta, Anísio..."

$J M$ : Penso que a gente não avança se não conseguir trazer Anísio de volta. Esse descompromisso com a história. $\mathrm{O}$ conjunto das coisas que ele produziu e materializou é impactante, porque uma coisa é ficar escrevendo e outra coisa é ir para frente de batalha. Brigar no Senado, diálogos dele com os deputados... Ele produziu, se expôs. Muito obrigada!

\section{REFERÊNCIAS}

BURKE, P. Cultura, Tradição, Educação. In: GATTI, JR., D.; PINTASSILGO, J. (orgs.). Percursos e desafios da pesquisa e do ensino de história da educação. Uberlândia: EDUFU, 2007. p. 13-24.

CARVALHO, F.G. de. As pequenas comunidades rurais e o oficio de ensinar: de professor leigo a funcionário municipal (1940-2000). Tese (Doutorado em Educação) - Universidade Federal do Rio de Janeiro, Rio de Janeiro, 2013. Disponível em: <https://ppge.educacao.ufrj.br/ppge-teses-2013.html>. Acesso em: 17 jun. 2019.

CUNHA, L.A.C.R. Educação, Estado e Democracia no Brasil. 3. ed. São Paulo/ Brasília/Niterói: Cortez/FLACSO/EdUFF, 1999.

EBOLI, T. Uma escola diferente. São Paulo: Cia. Editora Nacional, 1969.

MENDONÇA, A.W.; XAVIER, L.N. Por uma política de formação do magistério nacional: o Inep-MEC dos anos 1950-60. Brasília: INEP-MEC, 2008. Disponível em: <http://portal.inep.gov.br/informacao-da-publicacao/-/asset_ publisher/6JYIsGMAMkW1/document/id/492403 >. Acesso em: 17 jun. 2019.

PINHEIRO, J.G. da R. O Diário de Dalila: poética, testemunho e tragédia na formação escolanovista do individuo moderno (1933-1934). Tese (Doutorado em Educação) - Universidade Federal da Paraíba, João Pessoa, 2015. Disponível em: <https://repositorio.ufpb.br/jspui/bitstream/tede/8675/2/arquivototal.pdf $>$. Acesso em: 17 jun. 2019.

RIBEIRO, D. Confissóes. São Paulo: Companhia das Letras, 1996.

TEIXEIRA, A. Educação não é privilégio. São Paulo: Cia. Editora Nacional, 1957. 


\section{NOTAS}

1. O Programa Bolsa Família compóe uma política social que articula renda mínima, segurança alimentar, frequência escolar e cuidados com a saúde de crianças entre zero e dezessete anos de idade, de famílias em estado de vulnerabilidade (pobreza extrema). Atende a famílias de todos os estados brasileiros, desde 2003, quando se iniciou o primeiro mandato do Presidente Luís Inácio Lula da Silva, do Partido dos Trabalhadores.

2. César Coll Salvador é professor da Faculdade de Psicologia da universidade de Barcelona, Espanha, onde coordenou uma reforma do ensino, em 1990. Como consultor do Ministério da Educação (MEC) entre 1995 e 1996, colaborou na elaboração dos Parâmetros Curriculares Nacionais (PCN), publicado em 1997, como guia de orientação curricular para as escolas brasileiras de educação básica.

3. Referência à Conferência de Abertura proferida pela Professora Clarice Nunes na 23a Reunião Nacional da Associação Nacional de Pós-Graduação em Educação (ANPEd), Caxambu-MG, setembro/2000. Cf: NUNES, C. Anísio Teixeira: a poesia da ação. Revista Brasileira de Educação, n. 16, p. 5-14, jan./abr. 2001. Disponível em: <http:// www.scielo.br/pdf/rbedu/n16/n16a01>. Acesso em: 17 jun. 2019.

Recebido em 20 de março de 2019.

Aprovado em $1^{\circ}$ de julho de 2019. 